\title{
Periodismo cultural en la postmodernidad
}

\author{
Rosa María Arráez Betancort \\ Universidad Europea Miguel de Cervantes \\ rarraez@uemc.es \\ Elvira JENSEN CASADO \\ Universidad Europea Miguel de Cervantes \\ mejensen@uemc.es \\ Carolina PASCuAl PÉREZ \\ Universidad Europea Miguel de Cervantes \\ cpascual@uemc.es
}

\begin{abstract}
Resumen:
Con el objeto de llevar a cabo un periodismo cultural de calidad, y en concreto cinematográfico y literario, los periodistas necesitan formarse al respecto de la postmodernidad y el postmodernismo cultural en que se desarrolla la sociedad y que para algunos expertos ha derivado ya en hipermodernidad. El arte actual genera imaginarios que modifican la realidad contemporánea. Por lo tanto, literatura y cine producen nuevos modos de mirar el mundo y se relacionan lógicamente entre sí de forma post o hipermoderna. En este contexto sociocultural, el ciudadano requiere del trabajo periodístico para criticar cualquier fenómeno y distinguir el valor de cualquier obra frente al asedio del marketing y la publicidad.
\end{abstract}

Palabras clave: postmodernidad; periodismo cultural; postmodernismo cultural; cine; literatura

\section{Cultural Journalism in postmodernity}

\begin{abstract}
:
In order to have a quality cultural journalism, more specifically cinematographic and literary, the journalists need to learn about postmodernity and cultural postmodernism that emerges in this society and that some experts thinks has resulted in hypermodernity. Today's art creates imaginaries that modify our contemporary reality. Therefore, literature and cinema produce new manners to see the world and they will logically relate to each other in a post or hypermodern way. In this sociocultural context, the public needs the journalist's work to be able to criticize any event or to distinguish the value of any art work facing the marketing and advertising siege.
\end{abstract}

Keywords: postmodernism; cultural journalism; cultural postmodernism; cinema; literature

\section{Referencia normalizada:}

Arráez Betancort, R. M., Jensen Casado, E. y Pascual Pérez, C. (2014): Periodismo cultural en la postmodernidad. Historia y Comunicación Social. Vol. 19. Núm. Especial Marzo. Págs. 49-61.

Sumario: 1 .Introducción y metodología: la complejidad del periodismo cultural. 2. Postmodernidad y postmodernismo cultural. 3. Relaciones de la literatura y el cine postmodernos en la creación de imaginarios. 4. Relación entre el cine y literatura. 5. Conclusión: papel del periodismo cultural. 6. Bibliografía 


\section{Introducción y metodología: la complejidad del periodismo cultural}

Hacer periodismo cultural, y en este caso literario y cinematográfico, resulta complejo en la postmodernidad. Además, autores como Lipovetsky y Serroy (2010:7) han calificado estos últimos años como hipermodernos, planteando el surgimiento de una nueva fase denominada hipermodernidad que ha transformado profundamente:

el relieve, el sentido, la superficie social y económica de la cultura (...): se ha convertido en mundo, en cultura-mundo, cultura del tecnocapitalismo planetario, de las industrias culturales, del consumismo total, de los medios y de las redes informáticas.

El profesional del periodismo debe saber comunicar una postura crítica más allá de cualquier definición, siguiendo a Rodríguez Pastoriza (2006:16). Es más, según este autor, el profesional de la información debe incluir "los problemas de la sociedad y de la época en la que vive" en sus textos periodísticos, además de "saber interpretar la potencialidad crítica de los creadores" culturales y transferirla a los receptores con todas las consecuencias, "apelando a su formación" y considerando siempre su responsabilidad. La cultura debe ser entendida como "la producción de fenómenos que ayudan a cambiar y a transformar el sistema social". Por lo tanto, el periodismo no puede dar la espalda a la postmodernidad y sus variantes.

El periodismo cultural ejerce un papel relevante en la difusión y divulgación tanto de la literatura como del cine, en la divulgación y potenciación de cultura, ya sea a través de lecturas literarias o por medio de la contemplación de trabajos cinematográficos, o mediante su contextualización social, política, económica, etc. y la de sus creadores, por ejemplo. Dada la escasa bibliografía en periodismo cultural, literario y cinematográfico, se hace necesaria una contribución a la formación de periodistas expertos en cine y literatura, para que estas artes tengan una mayor difusión como hechos culturales y así enriquecer el periodismo cultural. Con esta propuesta a modo de ensayo, recopilando bibliografia procedente de expertos en comunicación, cine, literatura, sociología y filosofía principalmente, se pretende ayudar a los profesionales en periodismo para que sus análisis de los hechos culturales se completen con un pertinente conocimiento de sus contextos. La postmodernidad, la literatura y el cine ayudan a los periodistas culturales. Un mayor conocimiento de la literatura, una mejor comprensión de los recursos del cine, y el papel de ambos en la producción de imaginarios, así como un mejor entendimiento de la postmodernidad e hipermodernidad permite un desempeño periodístico profesional de calidad. No se trata solamente de mejorar la crítica cultural sino también de la puesta en práctica de otros géneros periodísticos como, por ejemplo, la entrevista, la crónica o el reportaje.

Si se entiende la cultura como un área temática próxima al periodismo y a sus intereses, han de distinguirse, siguiendo a Giner, Lamo de Espinosa y Torres (1998: 168-170) dos ideas de cultura en las que se interviene periodísticamente: por un lado, cabe la idea de cultura como un todo ya que el periodismo interviene divulgando versiones de la realidad intencionadamente o no: creencias, lenguaje común, ideas, normas, valores, símbolos, etc. Y, por otro lado, se ve también la cultura como un 
conjunto de artes en que se situaría la literatura y el cine. El papel del periodismo en la divulgación de la cultura en general y postmoderna en particular, desde estos dos puntos de vista, resulta indiscutible. De este modo, afrontar la postmodernidad ayuda a entender el presente.

\section{Postmodernidad y postmodernismo cultural}

Esteban (2013:11) sintetiza el pensamiento de Lipovetsky sobre la hipermodernidad cuando manifiesta que tras la postmodernidad "la radicalización moderna de la autonomía individual ya no se expresa como hedonismo de superficie sino como decepción". Esta nueva fase se asentaría en una "cultura-mundo" basada en el consumo y en el mundo como pantalla. La pantalla global respaldada por la tecnología produce una "mutación cultural que afecta radicalmente a la creación y a la propia existencia", siguiendo a Lipovetsky y a Serroy (Esteban, 2013:11). Y el cine, la literatura y el propio periodismo tienen su papel en la generación de imaginarios. Puesto que esta nueva idea de hipermodernidad deriva de la postmodernidad conviene saber que los fundamentos que permiten a un periodista comprender la postmodernidad y el postmodernismo cultural se centran en entender sus características, causas y consecuencias, intentando relacionarlas con los medios de comunicación y, en concreto, con el ejercicio del periodismo. Esta etapa denominada postmoderna tiene lógica al cuestionar la Modernidad que la antecede con sus aspiraciones universales, la imposición del pensamiento ilustrado, una idea de sujeto, etc. Como menciona Navajas (2008:31), es evidente que la postmodernidad se debe definir como "una revisión crítica de las últimas ramificaciones" de las nociones sistemáticas que componen el proyecto moderno. Se ha producido una disolución de los hasta ese momento grandes modelos y principios que han mantenido los órdenes sistemáticos.

Los grandes paradigmas de la etapa moderna se cuestionan en la postmodernidad, según Imbert ((b)2010:12), pero la pretensión de generar seres humanos autónomos no se consigue porque priman las democracias mediáticas, el relativismo y el nihilismo. La importancia de las nuevas tecnologías de la comunicación y de la información se encuentra en el traspaso de las limitaciones de espacio y tiempo, favoreciéndose el desarrollo de una cibercultura y nuevos procesos comunicativos. Frente a los avances de las nuevas tecnologías se incide en el ser humano, se discute sobre lo real. La supremacía de la velocidad y la necesidad de inmediatez... se producen junto con la hegemonía de los montajes derivados de los medios de comunicación. Se esfuman los límites entre lo real y lo virtual y se ponen en duda los mecanismos de percepción sobre los que se construía la realidad en la etapa moderna. Como menciona Llorca (2010), se debate la manera en que se legitima el conocimiento. Simultaneidad, fragmentación y mercantilización repercuten en la posibilidad de conocer. En contraposición con el pasado y sus planteamientos, la investigación actual es fragmentaria, parcial y tentativa. Son visiones subjetivas sin intenciones de validez general, tal y como afirma Navajas (2008:35).

Casi todas las teorías postmodernas estudian los límites entre disciplinas académicas como filosofía, ciencias sociales, economía, literatura, etc. para producir un 
discurso supra disciplinar. Critican los ideales de representación, de verdad, racionalidad o coherencia, entre otros, tan característicos de teorías modernas, al igual que conceptos sobre el sujeto, significado y causalidad, parafraseando a Best y Kellner (1991:256-298). Es más, se considera que se ha producido una erosión entre los términos alta y baja cultura como consecuencia de la eliminación de los textos canónicos. El efecto es una crisis del papel del intelectual, amenazado con la obsolescencia en las sociedades tecnocráticas donde las ciencias, cada vez más, desplazan a las humanidades. El discurso postmoderno ha dado la oportunidad a algunos intelectuales de posicionarse como pensadores innovadores para conseguir nuevas fuentes de capital cultural.

Por lo tanto, las consecuencias de la postmodernidad se perciben al no prosperar su reclamo de humanización, entorpecido por las democracias mediáticas. Se asiste a una radicalización del consumismo y las relaciones sociales globales destierran lo individual. Brotan nuevos imaginarios procedentes de esos nuevos procesos comunicativos de la postmodernidad porque como plantea Barbancho (2011:68), la postmodernidad es "la mirada que mira a través de unas gafas deconstructivas". Y pone de manifiesto si al llevarse a cabo este proceso no se estaría generando una nueva forma de mirar el mundo.

Los autores más críticos como Lyotard (1987: 99) se cuestionan si la humanidad está capacitada para afrontar el laberinto que la rodea, al margen de las simplificaciones procedentes de las nuevas tecnologías. Según Baudrillard (Lyon, 2000:41), la superioridad de los montajes afecta definitivamente la comprensión de la realidad, porque se asiste a una burla de los viejos marcadores de significados, tal y como concluye Llorca (2010). La visión tamizada de lo que ocurre impide el contacto directo con lo que se entiende clásicamente como real y este cambio sobre la percepción de lo real aqueja al conocimiento mismo, su producción y acceso. A la vez, los críticos demandan mayor reflexión desde propuestas neopositivistas o desde el positivismo reflexivo, como sucede desde el ámbito científico con Elías (2008) y Zamora (2005). Algunos autores como Lyon (2000:20 y 22) e Imbert ((b) 2010:12) reclaman la ética ante el exceso de visibilización y el juego de la identidad.

En lo que atañe específicamente al postmodernismo cultural, la Segunda Guerra Mundial supuso un antes y un después en el arte. Los movimientos artísticos sospechan de la tradición y por ello las obras culturales no se rigen por reglas preestablecidas y se oponen a cualquier categoría que permitan su enjuiciamiento. Se concibe el arte como expresión libre de cualquier deseo y prevalece la mezcla de estilos, el collage. Frente a etapas anteriores, el público tiene una función en la producción cultural al influir en los artistas. La sociedad de consumo y sus consumidores desempeñan un papel importante, dejando de lado la idea de ciudadano. Actualmente impera el entretenimiento para que nuestra mente descanse y, por lo tanto, la industria del entretenimiento, según Muñoz de Baena (2011:136-137); una industria labrada a medida de ese tiempo fungible, abstracto y formalizado, copia del patrón monetario. La cultura está obligatoriamente destinada a producir conformidad y a producir productos de consumo rápido y sencillo. 
Según Calinescu (2003:147) y a modo de crítica, el arte postmoderno es gratuito, comunal, opcional y anárquico. Se culpa a los artistas de renegar de la coherencia, de las ideas, de la complejidad, de la ironía, de conflictos éticos, etc., en favor de lo antirracional, apocalíptico, romántico y sentimental, e irresponsable proféticamente, según sus palabras. En este sentido, se origina una reivindicación de la función del arte en el momento postmoderno en que vivimos, se busca un papel más activo en que no se huya de la complejidad para asegurar su supervivencia. Beriain (2008:178-179) afirma que la creatividad "necesita tiempo libre" para su evolución en un momento en que domina la inmediatez, la velocidad..., alertando sobre el riesgo de la decadencia, de la caótica mezcla de estilos. Tras una supuesta democratización cultural se oculta la manipulación de un mercado de masas. El consumo de arte postmoderno, como menciona Olsen (1987:8), es un tipo de autoconsumo, una anti-creación, bien sea a través de un impulso hacia el silencio, agotamiento de la imaginación, una sensación de impotencia y entropía o bien a través de un impulso de explosión cacofónica, una liberación de la imaginación, una sensación de improvisación fuera de control.

De acuerdo con Esteban (2013:11), narrar equivale a un "ejercicio de representación abstracto que se deja invadir por la memoria y que se proyecta en la imaginación". La tensión entre la ficción y lo real se produce tanto dialéctica como dialógica y trágicamente y "va del reflejo mimético y de la reproducción, al intento de modificar y transformar esa realidad construida". Pero cómo se origina, por ejemplo, la memoria post o hipermoderna. $\mathrm{O}$, también, de qué manera el cine y la literatura, y el periodismo, reflejan y transforman la realidad contemporánea mediante los imaginarios simbólicos y sociales que proyectan y producen en "el contexto de la hipervisibilidad y del consumo total", siguiendo a este autor.

\section{Relaciones de la literatura y el cine postmodernos en la creación de imagina- rios}

Dice Imbert (2013:15) que el cine de por sí es imaginario. También lo es el arte y, por lo tanto, la literatura. Y lo hace, entiéndase que el arte en general y el cine o la literatura en particular, de dos formas: por una parte, como imaginación e invención, y, por otra, como "cámara de eco del imaginario colectivo, soporte y polea de transmisión de las representaciones sociales" (Imbert, 2013:15-19). Los individuos se reconocen como seres sociales y en esas representaciones se expresan "obsesiones, deseos y fobias" que se anclan en el inconsciente colectivo. En este caso y del mismo modo, tanto al periodismo como a los medios de comunicación, se les atribuye las funciones mimética y proyectiva o imaginaria. Esta última función, siguiendo a Imbert (Ibid.), alude a "un texto flotante, a veces informe, que revela estructuras profundas (de orden semántico y simbólico)". Periodismo, literatura y cine lo concretan tanto estética como narrativamente. He aquí a los imaginarios que en el caso del cine y la literatura desde los 90, de sus historias, se canalizan mediante la ficción porque no encuentran su sitio en el discurso público o en la racionalidad, interviniendo en la realidad y la 
identidad individual y colectiva. La postmodernidad cinematográfica y literaria como "espacio de deconstrucción", enfrentamiento, duda y "cuestionamiento" de objetivos. Como un instrumento de proyecciones más que de identificaciones.

La literatura en su concepción más amplia, como narración, lleva implícita la influencia de un desarrollo de hechos en torno a unos procesos históricos y existenciales determinados. Señala Navajas (2008:13), cómo en la novela actual lo utópico, así como lo distópico y apocalíptico han sido determinantes, en cuanto a la capacidad de crear "nuevos modos de realización de la sociedad y de las relaciones humanas". Siguiendo a Zavala (2007:191), se podría afirmar que en la literatura postmoderna, lo Real aparece en la esfera de la muerte, del horror y del delirio, es decir en lo inconceptuable, aquello difícil de imaginar o representar. El sujeto se ve incapaz de organizar su pasado y su futuro, y le queda un conjunto de fragmentos. En esa misma línea, Navajas considera que a diferencia de épocas pasadas, la exploración de la realidad que rodea al individuo es "parcial, fragmentaria y tentativa", lo que trae consigo una incursión en la narración de visiones subjetivas protagonizadas por "la nostalgia, las memorias sublimadas, el deseo frustrado, más que el raciocinio sistemático" (Navajas, 2008: 35).

Si se tiene en cuenta la idea de hipercine de Serroy (Esteban, 2013:12), se asiste actualmente a una cuarta etapa cinematográfica en la que el cine ha traspasado la propia modernidad por haberse constituido como modo de existencia. El hipercine se erige frente al cine procedente de la modernidad primitiva de una primera etapa, de la modernidad clásica como modelo de representación reconocible con claridad, iconicidad narrativa propia y como fenómeno industrial de una segunda, y una modernidad vanguardista y emancipadora de la tercera etapa que cuestiona valores y estrategias de la modernidad, mediante la búsqueda de nuevas estéticas y narrativas. Este nuevo cine está carente de reglas, es una suerte de experimentación continua en cuanto a los límites del cuerpo, la identidad, lo real, lo aceptable... No es sólo una manifestación sociocultural sino que ya es la cultura y la sociedad misma. De nuevo, procede recordar cómo Imbert (2013:15) analiza la capacidad del cine para producir cambios en las mentalidades y como indicador de "rupturas" y "mutaciones" en la configuración de identidades sociales mediante los imaginarios que transmite.

Según Zavala (2007:137), y a pesar de la dificultad de establecer unos rasgos propios para todas las películas postmodernas, y siendo una característica distintiva de la postmodernidad que también podríamos aplicar a la literatura, se pueden resumir los siguientes elementos:

En síntesis, el cine posmoderno tiene un inicio narrativo y descriptivo acompañado por un simulacro de intriga de predestinación, la imagen tiene cierta autonomía referencial, el sonido cumple una función alternativamente didáctica, sincrónica o sinestésica, la edición es itinerante, la puesta en escena tiende a ser autónoma frente al personaje, la estructura narrativa ofrece simulacros de metanarrativa, el empleo de las convenciones genéricas y estilísticas es itinerante y lúdico, los intertextos son genéricos con algunos recursos de metaparodia y metalepsis, y el final contiene un simulacro de epifanía. Todo ello es consistente con una ideología de la incertidumbre, organizado a partir de un sistema de paradojas. 
La postmodernidad afecta al cine y a la literatura postmodernos con la incertidumbre presente en la metanarratividad, intertextualidad y metaparodia, y ante la dificultad de establecer fronteras entre distintos géneros artísticos de ficción, entre cine tradicional y cine experimental o entre cine y documental, etc. en cualquier caso, cabe también replantearse la relación entre las ficciones cinematográficas y las cotidianas, extraídas de algún modo de las películas que se ven. Los expertos reconocen la transdisciplinariedad en aras de una mayor riqueza cultural y lejos de la idea despectiva de pastiche, de la estética de pastiche como sustitución del estilo, siguiendo a Murcia (2009: 104-105):

al contrario de lo que ocurriera con el estilo, vendría a hacer desaparecer la individualidad en aras de una canibalización aleatoria y puramente estética de los elementos formales y de contenido del pasado. La estética del pastiche, como imitación de un estilo peculiar o único y como parodia vacía, al tiempo que convierte la obra en un texto huero, hinchado gracias a la inter-textualidad, traería como consecuencia la transformación de la historia en un conjunto desfondado de imágenes y de textos... tendría que ver con el apetito social por consumir un mundo transformado en imágenes, las cuales se habrían alzado ahora como la nueva forma de reificación de la mercancía.

Transdisciplinariedad e intertextualidad sirven para dejar una huella identificativa del autor, ya sea en el cine o en la literatura. Los textos fílmicos postmodernos, así como los literarios son intertextuales. En ellos confluyen elementos de cultura popular y de cultura elitista, temas y valores clásicos, etc., que se revisan desde parámetros postmodernos.

El cine postmoderno parece también separarse de la tradición cinematográfica anterior, según Civila de Lara (2013:1) al exigir una capacidad perceptiva más activa al espectador, diferente a la que estaba acostumbrado, y dada la confusión de géneros, los cambios de ritmo, giros en el argumento, perspectivas diferentes, confusión entre protagonistas y antagonistas... Pero también la metanarratividad caracteriza al cine y a la literatura postmodernos como un intento de narrar el propio hecho de narrar, dejando constancia del proceso como un elemento de artificio del que hace uso el cine.

El fragmentarismo también caracteriza al texto fílmico y al texto literario al presentarse en una serie de escenas en apariencia inconexas e incluso paradójicas en las que el espectador o el lector deberá hacer el esfuerzo por darle sentido. Según Imbert, con este fragmentarismo se refleja la incertidumbre de la sociedad postmoderna sin un proceso histórico lineal y continuo que ha sido desbancado por el poder del presente, de lo simultáneo y por el carácter efímero de lo que rodea al ser humano. Como señala Zavala (2007: 137), en los filmes postmodernos no se representa la realidad sino que se presenta artísticamente mediante la ironía o la parodia que rompe con los cánones establecidos. De la misma manera, los textos literarios harán uso de la parodia para presentar los problemas que acucian a los personajes o el carácter de los propios personajes. 
Los planteamientos temáticos son nuevos en cuanto a la forma de presentarse. Imbert ((a) 2010: 16-39) habla de "el cine como experiencia de los límites" y sintetiza algunos de estos temas y sus características por su presencia constante: el cuerpo que se mueve entre la carencia y el exceso, como elemento de culto en una lucha desesperada e inútil contra el paso del tiempo, como frontera entre la propia identidad y la relación con el otro, como expresión de sentimientos y señas del malestar contemporáneo, como reflejo de un sexo evidente e invisible indicador de una sensación de vacío que hace que el individuo se encuentre perdido, sin un proyecto de futuro. La presencia de la violencia se muestra entre lo hipervisible y lo invisible y la percepción de la realidad, que oscila entre lo ultrarreal y la fantasía. Para el cine posmoderno, el cuerpo es un elemento de comunicación crucial donde el lenguaje verbal es secundario frente a la expresión corporal.

La muerte también se presenta como una temática constante en la filmografía postmoderna y relacionada con el cuerpo y la violencia. Como plantea Imbert ((a) 2010: 388) se consigue hacer de "la violencia un objeto recurrente e inofensivo, que satura nuestro universo de representación e incide en lo que he llamado la hipervisibilidad moderna". Al exponer al individuo a este tipo de imágenes y su sentido de lo real queda anulado y se recrea en escenas virtuales que muestran una realidad transformada en objeto de consumo. Estas representaciones de la muerte y la violencia, desde sus distintas perspectivas se concretan en dos tendencias: el interés por una vuelta a lo primario, dejando a un lado una visión tradicional y aportando nuevas sensibilidades que deriva en un ultrarrealismo y, por otra parte, el intento de abandonar la realidad inmediata para entrar en mundos fantasmagóricos, oníricos, que Imbert ((a) 2010: 559-569) denomina lo espectral. Se representan mediante una mirada extática ante la realidad y el espanto. La muerte y la violencia están vinculadas al espacio en que se enmarcan, normalmente referenciando el medio urbano, que representa la soledad del individuo en la sociedad postmoderna. Estos espacios equivalen a no lugares por los que transita el sujeto sin dejar ningún rastro a su paso y se caracterizan porque indican una interconexión, son transicionales, presentan un estancamiento del tiempo, el anonimato del individuo y la pérdida de su identidad, así como espacios que favorecen la incomunicación (Imbert (a) 2010:253-254). Estos no lugares son protagonistas en muchas de las novelas posmodernas, hoteles, aeropuertos, grandes ciudades, en los que las vidas de los individuos pasan desapercibidas, o en los que se favorece la creación de identidades falsas de los individuos protagonistas. Cuando se señalan estas temáticas como preponderantes en el cine y la literatura se está reconociendo la generación de imaginarios.

\section{Relación entre el cine y literatura}

Entendiendo los imaginarios como un instrumento de proyecciones más que de identificaciones, cabe detenerse a considerar cómo se proyecta la literatura en el cine hiper y postmoderno. Precisamente, el continuo juego con los modelos del cine actual 
se refleja incluso a nivel narrativo en el reciclaje, las versiones... No se trata tanto de mimetizar o imitar al cuestionarse los modelos establecidos sino de deconstruir los relatos y sus héroes. El cine postmoderno expresa los límites y hace uso de elementos narrativos, frases de guiones cinematográficos anteriores sin relación con los textos originales.

$\mathrm{Al}$ analizar películas o documentales del momento actual, puede encontrarse en ellos la mirada postmoderna del cine sobre los fenómenos literarios pasados, presentes y futuros o sobre la literatura misma. Que la literatura ha sido una fuente de inspiración y base de argumentos fílmicos es un hecho, sin embargo esto no significa que deba supeditarse la literatura al cine, sino que se trata de una influencia recíproca. Existen directores cinematográficos que en ocasiones son sus propios guionistas y crean las historias que les interesa llevar a la pantalla. Es el caso de Pedro Almodóvar, M. Armendáriz, Carlos Saura, Itziar Bollaín, Woody Allen, Quentin Tarantino, Alejandro Amenábar, Julio Medem, entre otros tantos. Pero al hablar de la relación entre literatura y cine parece obligatorio hacer alusión a las adaptaciones cinematográficas de obras literarias. Para Sánchez Noriega $(2000,47)$ la adaptación consiste en:

(...) el proceso por el que un relato, la narración de una historia, expresado en forma de texto literario, deviene, mediante sucesivas transformaciones en la estructura (enunciación, organización y vertebración temporal), en el contenido narrativo y en la puesta en imágenes (supresiones, compresiones, añadidos, desarrollos, descripciones visuales, dialoguizaciones, sumarios, unificaciones o sustituciones), en otro relato muy similar expresado en forma de texto fílmico.

Teniendo en cuenta esta definición de lo que supone el proceso de adaptación de una obra literaria al cine, se han establecido tres tipos de adaptaciones cinematográficas a partir de la nomenclatura utilizada por la crítica literaria para referirse al grado de representación de la realidad de una obra literaria. De este modo, siguiendo la teoría de Scholes y Kellog que recoge Manzano (2008: 121-122), atendiendo al grado de semejanza de la película con la obra literaria original de la que procede, en un primer caso, se trataría de crear duplicados o imágenes artísticas de un modo real, sería una adaptación mimética; en un segundo caso, se buscaría sugerir, por medio de las convenciones del arte, aspectos de una realidad sin pretensiones de ceñirse al mundo objetivo, y se trataría de una ilustración. Y por último, un tercer caso, en el que el film estaría inspirado en la realidad del texto, en una adaptación libre.

Sin embargo, al hablar de la relación entre la literatura y el cine deberíamos ir más allá, y valorar la intertextualidad que se produce entre ambas disciplinas, elemento caracterizador del posmodernismo cinematográfico ya citado. Siguiendo a Peña-Ardid (2009: 15), el nuevo texto supone "un mosaico de citas relacionado con otros enunciados homogéneos o pertenecientes a sistemas semióticos de diversa naturaleza", lo que supone que el lector/espectador podrá reconocer una serie de referencias explícitas o no, así como estructuras y lenguajes que su experiencia considera propios de un determinado sistema trasplantado a otro. 


\section{Conclusión: papel del periodismo cultural}

Por lo tanto, es trabajo de un periodista especializado en cultura adecuar un mensaje relevante como el postmoderno e hipermoderno a sus audiencias sea cual fuera su perfil. El público necesita conocimientos o herramientas que le ayuden a cuestionar o criticar cualquier fenómeno, en nuestro caso literario y cinematográfico, con el objeto de distinguir obras de calidad en oposición a la carencia de ideas, de conflictos éticos, a la falta de complejidad y coherencia tanto de estructuras literarias como cinematográficas. Y frente al asedio del marketing y la publicidad. Porque los autores más relevantes de la postmodernidad ni son populares, ni accesibles para la mayoría. El sometimiento del arte al marketing obliga a crear según las exigencias del mercado y al surgimiento de artistas populares a los que se les cuestiona su calidad artística. Siguiendo a Vargas Llosa (2012:37):

la literatura "light", como el cine "light" y el arte "light", da la impresión cómoda al lector y al espectador de ser culto, revolucionario, moderno, y de estar a la vanguardia, con un mínimo esfuerzo intelectual. De este modo, esa cultura que se pretende avanzada y rupturista, en verdad propaga el conformismo a través de sus manifestaciones peores: la complacencia y la autosatisfacción.

Este autor resalta la crisis que padece desde hace años la crítica en los medios informativos. Su función de asesoramiento ha quedado relegada a la diversión y la frivolidad. Y de ahí la necesidad de una formación periodística en la postmodernidad y el postmodernismo cultural. Los periodistas deben ser capaces de contextualizar los fenómenos culturales, literarios y cinematográficos que les rodean. Pero no sólo se trata de opinar sino también de informar e interpretar sobre temas culturales que afecten a la sociedad postmoderna.

En la postmodernidad e hipermodernidad, el periodismo cultural se enriquece mediante su desenvolvimiento no sólo a nivel técnico o formal propio del manejo de los géneros periodísticos y de los distintos formatos, sino también en el plano del contenido del mensaje periodístico. En un mundo global, el periodismo cultural debe ir más allá de las gramáticas del cine o la literatura con el objeto de relacionarlos con lo que los engloba, intentando analizar lo que cine y literatura dicen sobre el mismo mundo, cómo lo reorganizan y cómo influyen en la percepción de las personas y en la reconfiguración de sus expectativas, siguiendo a Lipovetsky y Serroy (Esteban, 2009: 27).

Lyotard (1987: 111-112) reconoce la relevancia de la comunicación entre los artistas y su público pero insiste, además, en el papel responsable del arte, resistiendo y testimoniando. Y de igual modo le sucede al periodismo. Siguiendo los planteamientos del escritor J. Ovejero (2011: 100), el arte no ha cumplido con las promesas de democratización de la postmodernidad ante la pérdida de sentido. Y el periodismo tiene que recuperar también su papel fundamental en democracia. Periodismo cultural de calidad como generador de imaginarios. Periodismo como resistencia. 


\section{Bibliografía}

BARBANCHO, I. (2011). Mundos perdidos. Una aproximación tematológica a la novela postmoderna, 1980-2005. Madrid: CSIC.

BERIAIN. J. (2008). Aceleración y tiranía del presente. Barcelona: Anthropos.

BEST, S.; KELLNER, D. (1991). Postmodern Theory. Critical Interrogations. New York: Guilford Press.

CALINESCU, M. (2003). Cinco caras de la modernidad. Madrid: Tecnos y Alianza Editorial.

ELÍAS, C. (2008). La razón estrangulada. La crisis de la ciencia en la sociedad contemporánea. Barcelona: Debate

ESTEBAN, J. L. (2013). El imaginario cinematográfico y la sociedad hipermoderna. Valladolid: Universidad Europea Miguel de Cervantes.

GINER, S., LAMO DE ESPINOSA, E. y TORRES, C. (eds.) (1998). Diccionario de sociología. Madrid: Alianza.

IMBERT, G. (2010). a) Cine e imaginarios sociales. Madrid: Cátedra.

IMBERT, G. (2010). b) La sociedad informe. Postmodernidad, ambivalencia y juego con los límites. Barcelona: Icaria.

IMBERT, G. (2013). “Cine e imaginarios sociales”. En ESTEBAN, J. (ed.) (2013). El imaginario cinematográfico y la sociedad hipermoderna. Valladolid: Universidad Europea Miguel de Cervantes. p. 15-22.

LIPOVETSKY, G. y SERROY, J. (2010). La cultura-mundo. Respuesta a una sociedad desorientada. Barcelona: Anagrama.

LLORCA, G. (2010). Comunicación, aceleración y realidad. Ponencia presentada en Ciclo de Debate sobre la Aceleración Velocidad, Cultura y Comunicación en los Espacios Urbanos Contemporáneos. Universidad Europea Miguel de Cervantes y Museo de Arte Contemporáneo: Patio Herreriano de Valladolid. 14 de abril de 2010

LYON, D. (2000). Postmodernidad. Madrid: Alianza editorial.

LYOTARD, J-F. (1987). La posmodernidad. Barcelona: Gedisa.

MANZANO, C. (2008). La adaptación como metamorfosis. Transferencias entre el cine y la literatura. Madrid: Fragua.

MUÑOZ DE BAENA, JOSÉ LUIS. (2011). “Tiempo y literatura en la industria cultural". En ESTEBAN J. (ed.) (2011). Palabra y ficción. Literatura y pensamiento en tiempo de crisis cultural. Valladolid: Universidad Europea Miguel de Cervantes. p. 131-144.

MURCIA, I. (2009). “Copiar o crear. La postmodernidad desde el cine de Michelangelo Antonioni y Brian de Palma”. En: Rev. AISTHESIS, $\mathrm{n}^{\circ} 45$, Chile: Universidad Pontificia. p. 103-121.

NAVAJAS, G. (2008). La utopía en las narrativas contemporáneas (Novela/Cine/ Arquitectura). Zaragoza: Universidad de Zaragoza.

OLSEN, L. (1987). Ellipse of Uncertainty. Westport: Greenwood Press.

PEÑA-ARDID, C. (2009). Literatura y cine. Madrid: Cátedra.

RODRÍGUEZ PASTORIZA, F (2006). Periodismo cultural. Madrid: Síntesis. 
SÁNCHEZ-NORIEGA, J.L. (2000). De la literatura al cine. Teoría y análisis de la adaptación. Barcelona: Paidós Comunicación

VARGAS LLOSA, M. (2012). La civilización del espectáculo. Madrid: Alfaguara.

ZAMORA, J. (2005). Ciencia pública-ciencia privada. Reflexiones sobre la producción del saber científico. México: Fondo de cultura económica.

ZAVALA, I. (2011). La metáfora, la escritura y la verdad. En ESTEBAN, J. (ed.) (2011). Palabra y ficción. Literatura y pensamiento en tiempo de crisis cultural. Valladolid: Universidad Europea Miguel de Cervantes.

6.1 Artículos en publicaciones web:

CIVILA DE LARA, E. (2013). Aproximación al cine postmoderno: las maneras de hacer mundos de Jim Jarmusch. Disponible en: http://huespedes.cica.es/aliens/ gittcus/edu.html. [12-05-2013]

OVEJERO, J. (2011). La literatura entre el mensaje y la posmodernidad. Disponible en: http://www.letrashispanas.unlv.eduVol4iss1Ovejero.pdf. [12-01-2011]

ZAVALA, L. (2007). La ficción posmoderna como espacio fronterizo. Ciudad de México: (Tesis. Centro de estudios Lingüísticos y Literarios). Disponible en: http://www.sepancine.mx/attachments/Lauro_Zavala_. [17-05-2013]

\section{Las autoras}

Rosa María Arráez Betancort es Doctora en Periodismo por la Universidad Complutense de Madrid y Máster en Periodismo y comunicación científica por la UNED. Sus áreas de trabajo abarcan el periodismo especializado en cultura y ciencia. Profesora adjunta en la Facultad de Ciencias Humanas y de la Información de la Universidad Europea Miguel de Cervantes de Valladolid, en su faceta divulgadora científica en el área del periodismo cultural destacan artículos como Aceleración y postmodernidad en el microrrelato, Aplicación de la investigación en literatura y periodismo, La postmodernidad en Los Mundos sutiles del cineasta Chapero- Jackson, etc.

Doctora en filología germánica, sección inglés, por la Universidad de Salamanca. Actividad docente en la Universidad de Salamanca, Universidad Católica San Antonio y actualmente en la UEMC. Estancias en SCIC de la Unión Europea, Bruselas, Bélgica, en el John F. Kennedy Institut, Freie Universität, Berlín, Alemania y en Chapel Hill University, Carolina del Norte, EE.UU. Las líneas de investigación se centran principalmente en el teatro afroamericano contemporáneo como August Wilson pero también en otros temas más interdisciplinares como el microrrelato, el análisis del tratamiento de un Nobel en la prensa española literaria y de opinión o la aplicación de la investigación en literatura y periodismo, etc.

Carolina Pascual Pérez, es Licenciada de grado en Filología Hispánica por la universidad de Valladolid y ABD en literatura española contemporánea por la Universidad de Ohio State (Columbus, EE.UU.). Sus principales líneas de investigación son el análisis semiótico de símbolos en el teatro, cine, literatura, etc., así como la 
relación de la literatura con los medios de comiunicación y el estudio de la literatura española y portuguesa del siglo XIX. Ha participado en el proyecto de I+D+i (20092011) financiado por la Consejería de Educación de CyL titulado: "La Semana Santa en Valladolid y su provincia a través de documentos fotográficos y los periódicos: Hoja del Lunes y Diario Regional entre los años 1958-1984". Entre sus publicaciones destacan: "Símbolos e imágenes en La flor de mi secreto, de Pedro Almodóvar". IV Congreso Internacional de Análisis Textual. Símbolos e Imágenes (2007); "Cómo enseñar teatro a periodistas culturales en el EEES" en Contenidos docentes en el EEES; "Vargas Llosa: análisis del tratamiento de un Nobel en el periodismo literario de opinión español" en Studium. Revista de Humanidades; "Aceleración y posmodernidad en el microrrelato" en La aceleración. Velocidad, cultura y comunicación en los espacios urbanos contemporáneos. 